\title{
Mechanism for Tensile Strain Hardening in High Performance Cement-based Fiber Reinforced Composites
}

\author{
Prijatmadi Tjiptobroto \& Will Hansen \\ Department of Civil Engineering, University of Michigan, Ann Arbor, Michigan 48109, USA
}

(Received 4 February 1991; accepted 11 October 1991)

\begin{abstract}
The mechanism responsible for the improvement in tensile strain capacity of FRC (fiber reinforced concrete) as a result of the addition of high volume fraction of discontinuous fibers was investigated, using energy changes associated with cracking. The energy terms considered include: matrix fracture energy, matrix strain energy, debonding energy, fiber strain energy and fiber frictional energy.

Assuming that the first observed crack is also the failure crack, it was found that multiple cracking occurs in high performance FRC. In such composites the energy needed to open the critical cracks exceeds the energy needed to form a new crack. The analysis predicts that the major energy term determining this behavior is the fiber debonding energy.

Multiple cracking was observed in fiber reinforced small densified DSP (particles) containing a high volume fraction (higher than 3\%) of fine and short steel fibers. Because crack localization did not occur during multiple cracking, very large increases in total strain capacity were achieved with increasing fiber volume fraction. At $12 \%$ fiber volume fraction, a total strain capacity of about $0 \cdot 2 \%$ was measured from flexure tests; an increase of about 15 to 20 times over that of the plain matrix.
\end{abstract}

Keywords: Fibre reinforced concrete (FRC), discrete fibers, multiple cracking, tensile strain hardening mechanism.

\section{INTRODUCTION}

The brittleness of concrete is reduced by incorporating fibers, typically up to a volume fraction of $2 \%$, to form a composite known as fiber reinforced concrete (FRC). At these relatively low fiber volume fractions, the contribution of fibers is apparent in the post-cracking response, represented by an increase in post-cracking ductility due to the work associated with pull-out of fibers bridging a failure crack. However, improvements in other properties such as first cracking strength, tensile strain capacity and peak load are insignificant. ${ }^{\prime}$

With the advent of special processing methods and the use of superplasticizers, concretes of compressive strength of $200 \mathrm{MPa}$ or higher have been reported with fiber volume fractions of $6 \%$ or more. ${ }^{2}$ Flexural tests of this material reinforced with a high volume fraction of main reinforcement $(10 \%$ or more) have shown that this type of composite is substantially free of visible cracks up to yielding of the main reinforcement. ${ }^{2,3}$ The tensile strain capacity appears to be improved by a factor of 20 to 40 times over that of the plain matrix. Similar improvements in tensile strain capacity have been reported for other cement-based composites containing a high volume fraction of fibers. They include SIFCON (slurry infiltrated fiber concrete) reported by Naaman and Homrich ${ }^{4}$ and polypropylene fiber composites reported by Mobasher and coworkers. ${ }^{5-7}$

In these high performance composites, the densely spaced fibers can suppress the growth of

Cement \& Concrete Composites 0958-9465/92/\$5.00 @ 1992 Elsevier Science Publishers Ltd, England. Printed in Great Britain 
microcracks and prevent strain localization leading to failure. This substantially increases the strength and strain capacity of the composite.

\section{BEHAVIOR OF HIGH PERFORMANCE FRC IN TENSION}

Naaman \& Shah ${ }^{8}$ and Naaman ${ }^{9}$ have proposed that an inelastic strain region exists in a high performance FRC. This region, denoted as region II in Fig. 1(a), is a result of multiple microcracking and occurs between the end of the linear elastic range and the peak load. Since strain localization has not occurred, the multiple cracking stage will result in increases in bulk strain capacity of the composite.

The main difference in the tensile loaddeformation behavior between high performance and conventional FRC is in the multiple microcracking stage, which may not exist in conventional FRC, as shown in Fig. 1(b).

The linear elastic region, region $\mathrm{I}$, and the softening stage, region III, are present in both systems. The softening stage corresponds to the opening of a single failure crack and is mainly controlled by the fiber pull-out process. ${ }^{1(1-14}$ At this failure stage, the deformation is not characterized by strain, but rather by a crack-opening relationship.

The mechanism for improved tensile strain capacity of discontinuous fiber composites is not well understood. An energy approach, similar to the method used by Aveston, Cooper and Kelly (known as the ACK model) ${ }^{15}$ for continuous fiber composites, is used in this study for understanding the mechanism of tensile strain hardening of high performance discontinuous-fiber cement-based composites.

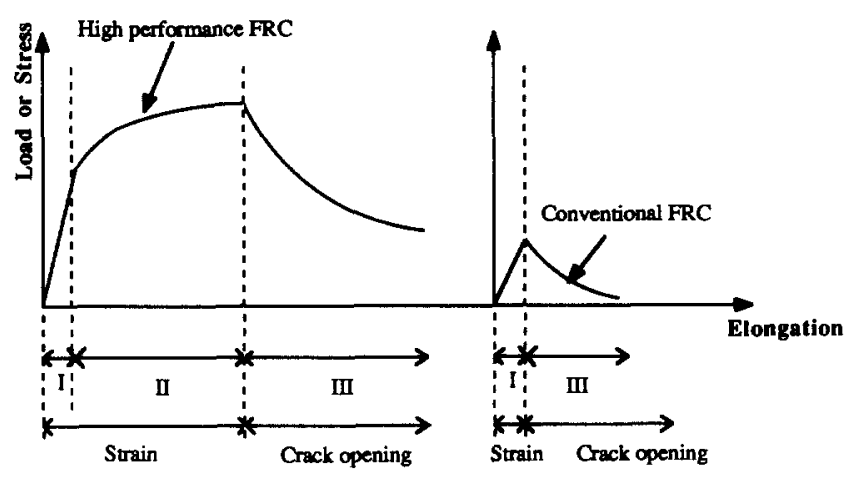

Fig. 1. Typical tensile load-elongation response for a (a) high performance FRC and (b) conventional FRC.

\section{EXPERIMENTAL}

\section{Materials}

A DSP (densified small particle) matrix is basically a high strength material which consists of a binder and aggregates. The binder is made from cement and a high content of microsilica with a very low water-to-cementitious ratio, while the aggregates are gap-graded quartz sands. Steel fibers are added to this DSP matrix to improve the performance by reducing the brittleness of the matrix material.

The cement used in this study was White Portland Cement from Aalborg Portland $\mathrm{A} / \mathrm{S}$, Aalborg, Denmark, with an estimated specific gravity of $3 \cdot 15$, an average diameter of 5 to $10 \mu \mathrm{m}$ and an estimated specific surface of 400 to 450 $\mathrm{m}^{2} / \mathrm{kg}$.

The microsilica used was Elkem (Elkem Materials A/S, Vaagsbygd, Kristiansan, Norway) (powder form) with an average diameter of 0.1 to $0 \cdot 2 \mu \mathrm{m}$.

A superplasticizer powder consisting of a sodium salt of highly condensed naphthalene sulphonate formaldehyde condensate was used.

The aggregates used were gap-graded quartz sands of $0-0 \cdot 25,0 \cdot 25-1$ and $1-4 \mathrm{~mm}$.

Brass coated steel fibers (Dramix) from Bekaert, Belgium, were used. They had a diameter of $0.15 \mathrm{~mm}$, a length of $6 \mathrm{~mm}$ and a tensile yield strength of $2950 \mathrm{MPa}$.

The mix proportions are shown in Table 1.

\section{Methods}

\section{Mixing}

A 10 liter pan mixer was used to prepare the mix. Cement, microsilica, quartz sand and superplasticizer powder were first dry-mixed for about $2 \mathrm{~min}$. Water was then added and mixing was con-

Table 1. Mix proportions of fiber reinforced DSP $\left(\mathrm{kg} / \mathrm{m}^{3}\right)$

\begin{tabular}{lrrrrr}
\hline Cement & 750 & 750 & 750 & 750 & 750 \\
Microsilica & 179 & 179 & 179 & 179 & 179 \\
Dispersing agent & 22 & 22 & 22 & 22 & 22 \\
Quartz sand & & & & & \\
$\quad 0-0.25 \mathrm{~mm}$ & 189 & 189 & 189 & 189 & 189 \\
$0 \cdot 25-1 \mathrm{~mm}$ & 383 & 383 & 383 & 383 & 383 \\
$\quad 1-4 \mathrm{~mm}$ & 460 & 536 & 613 & 690 & 766 \\
Water & 169 & 169 & 169 & 169 & 169 \\
Fiber & 913 & 685 & 457 & 228 & - \\
$V_{\mathrm{f}}$ target $(\%)$ & 12 & 9 & 6 & 3 & 0 \\
$V_{\mathrm{f}}$ actual $(\%)$ & 11.7 & 8.8 & $5 \cdot 8$ & 2.9 & 0 \\
\hline
\end{tabular}

Water $/$ cementitious ratio $=0 \cdot 18$. 
tinued for another $12 \mathrm{~min}$ before the fibers were added to the mix. Mixing was further continued for another $6 \mathrm{~min}$. Thus, a total of $20 \mathrm{~min}$ of mixing time was used. The long mixing time compared to 1 to 2 min of mixing for ordinary concrete is needed to obtain effective wetting of the ultrafine particles and a high degree of microhomogeneity. Also, the amount of dispersing agent used was considerably higher than in traditional FRC and was of a type that proved to be very effective in dispersing the cement and microsilica.

In order to prevent fiber grouping, the fibers were added in small quantities during the mixing process. The relatively long mixing time further distributed the fibers more evenly throughout the mix. Visual inspection of fractured surfaces of the specimens confirmed that the occurrence of fiber grouping was minimal.

The specimens were cast and vibrated simultaneously, using a vibratory table with a frequency of about $80 \mathrm{~Hz}$; the molds were securely fixed on the vibratory table. This method reduced not only the entrapped air bubbles, but also allowed the casting of very stiff mixes. The workability for mixes with a fiber volume fraction up to $6 \%$ was fairly good; however, for $12 \%$ fibers the mix was very stiff.

The principles for processing of densely packed particle systems, such as the DSP matrix, with a high fiber volume fraction, are discussed by Bache. $^{2}$

\section{Curing}

The total curing time was 4 days. One day at room temperature, two days in $80^{\circ} \mathrm{C}\left(176^{\circ} \mathrm{F}\right)$ water, and one day at room temperature.

\section{Flexure testing}

Beam specimens with dimensions of $50 \mathrm{~mm} \times 50$ $\mathrm{mm} \times 500 \mathrm{~mm}$ and a span length of $420 \mathrm{~mm}$ were loaded in third-point loading, as shown in Fig. 2, using an Instron model 1255 (Instron Inc., Canton, MA 02021, USA). Three specimens were tested for each fiber volume fraction.

To measure the strain, four strain gages of the type HBM 60 LY 51 were placed at the

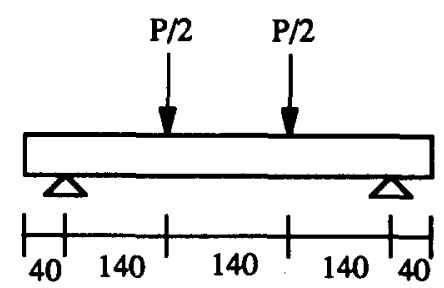

Fig. 2. Flexural test loading arrangement. mid-section of the beam; two were placed on the compression side, while the other two were placed on the tension side. The gage length was $20 \mathrm{~mm}$.

\section{Compression tests}

Compressive strength and elastic modulus of the DSP matrix were obtained from compression tests on $45 \mathrm{~mm} \times 90 \mathrm{~mm}$ cylinders.

\section{Matrix fracture energy tests}

The fracture energy of the DSP matrix was obtained from tests on notched beam specimens. The dimensions of the beams were the same as those used in the flexure tests, and the depth of the notch was $23.5 \mathrm{~mm}$. The average value of the fracture energy obtained from the tests was 120 $\mathrm{N} / \mathrm{m}$.

\section{RESULTS AND DISCUSSION}

\section{Strain hardening}

A typical load-tensile strain response in flexure for different fiber volume fractions is shown in Fig. 3. Only the strain gage response, averaged for two strain gages, is shown up to maximum load in Fig. 3, i.e. regions I and II (the softening region is not shown).

The strain hardening, which is an increase in strain under increasing load, in both the elastic and inelastic range is evident in Fig. 3. The strain capacity increased with increasing fiber volume fraction; from 150 microstrain (for the plain matrix) to about 2000 microstrain $(0 \cdot 2 \%)$ for $12 \%$ fiber volume fraction. Also evident from Fig. 3 is the increase in load-carrying capacity with increasing fiber volume fraction. For the plain

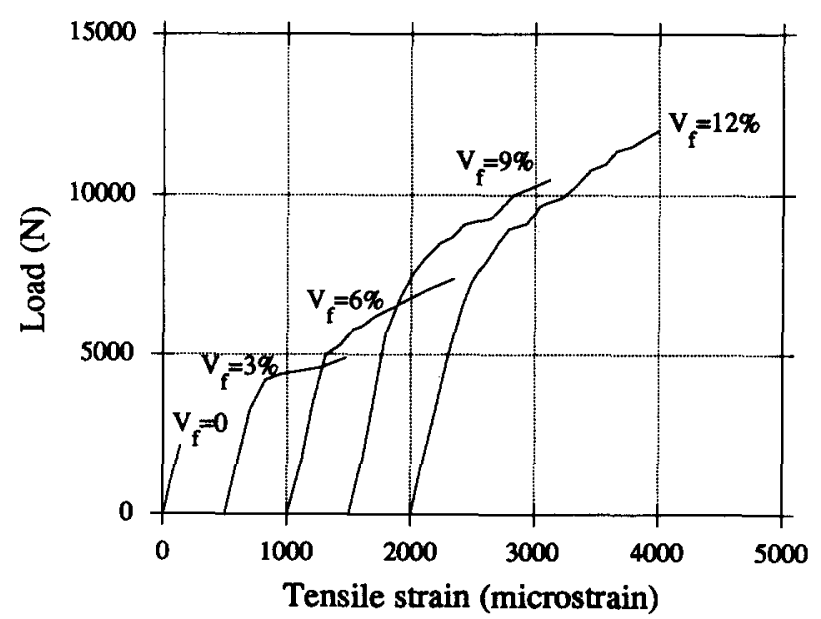

Fig. 3. Typical load-tensile strain response of DSP with different fiber volume fractions. 
DSP matrix the load level was relatively low, about $2500 \mathrm{~N}$, while for a $V_{\mathrm{f}}$ of $12 \%$ the maximum load level was about $12000 \mathrm{~N}$.

From these results it is clear that tensile strain hardening takes place in fiber reinforced DSP.

\section{Energy changes during cracking in continuous and discontinuous FRC}

The energy components involved during the deformation of FRC have been the subject of investigation by several researchers, particularly those of region III, which are often related to the energy absorption capacity of FRC. For regions I and II, energy relations were obtained for continuous aligned fiber composites. One of the most widely used models is the ACK model. ${ }^{15}$

According to the ACK model the following energy changes are assumed to occur during the formation of a crack:

- Work must be done in destroying the elastic bond between the fiber and the matrix $\left(\gamma_{\mathrm{db}}\right)$.

- The matrix must slide back over the fibers and the fibers also extend. Since the displacement of the fibers and matrix differ, work is done against the frictional force $\left(U_{\mathrm{s}}\right)$.

- The matrix loses elastic strain energy because the strain at the crack face decreases to zero $\left(\Delta U_{\mathrm{m}}\right)$.

- The elastic strain energy in the fiber increases because of the increase in strain at the crack face as a result of the crack-bridging action of the fibers $\left(\Delta U_{i}\right)$.

- Work must be done during the formation of the new surfaces, which is equal to the fracture energy of the matrix $\left(G_{\mathrm{m}}\right)$. The amount of work expended is $2 \gamma_{\mathrm{m}} V_{\mathrm{m}}$ (or $G_{\mathrm{m}} V_{\mathrm{m}}$ ).

The same energy components are used in this study on discontinuous FRC. The differences between the proposed model and the ACK model are in the timing of the occurrence and in the evaluation of the energy terms. Moreover, the debonding energy term is not included in the ACK equation. Comparison between the timing of occurrence of different energy terms between the proposed model and the ACK model is shown in Fig. 4. Notice that the ACK model does not differentiate between these two points, the first cracking point and the multiple cracking point, with respect to energy changes; all the energy terms are combined at the point of first cracking.

The model derived in this study assumes that the elastic bond between fiber and matrix is still present at the interface at point 1 . At point 2 it is assumed that the interfacial stress is frictional and uniform throughout the fiber embedment length. The assumption of no debonding at first cracking is reasonable for high performance FRC. Only in the case of a weak matrix and low debonding energy at the fiber-matrix interface will substantial debonding occur at the point of first cracking.

As shown in Fig. 4, point 1 corresponds to the occurrence of the first crack (microcrack) or, in Fig. 1, the end of region I. Between points 1 and 2, this microcrack starts to open up and at the same time other microcracks are formed in the composite. The energy required to open the first microcrack from point 1 to point 2 , which is the end of region II, denoted by $E_{1}(1 \rightarrow 2)$, is the sum of the debonding energy, fiber strain energy and frictional energy (shown in Fig. 4), and is given by eqn (1):

$$
E_{1}(1 \rightarrow 2)=\Delta U_{\mathrm{f}-\mathrm{mc}}+\Delta U_{\mathrm{fr}}+U_{\mathrm{db}}+U_{\mathrm{sb}}
$$

where

$\Delta U_{\mathrm{f}-\mathrm{mc}}=$ increase in the fiber strain energy as the result of the crack-bridging action of the fibers in the multiple cracking stage;

$\Delta U_{\mathrm{fr}}=$ frictional energy, which is the energy absorbed because of the difference in strain (slip) between the fiber and the matrix;

$U_{\mathrm{db}}=$ debonding energy, which is the energy required to destroy the elastic bond at the fiber-matrix interface;

$U_{\mathrm{sb}}=$ energy associated with the snubbing or pulley effect due to crack-bridging action of inclined fibers.

The energy required to form new microcracks, denoted by $E_{2}, E_{3}, \ldots, E_{n}$, is the sum of the matrix fracture energy, fiber strain energy and matrix strain energy (Fig. 4) and is given by eqn (2):

$$
E_{2}=E_{3}=E_{n}=G_{\mathrm{m}} V_{\mathrm{m}}+\Delta U_{\mathrm{f}-\mathrm{mu}}-\Delta U_{\mathrm{m}}
$$

where

$$
\begin{aligned}
G_{\mathrm{m}} V_{\mathrm{m}}= & \text { fracture energy of the matrix, which is } \\
& \text { the energy required to create a new } \\
& \text { surface; } \\
G_{\mathrm{m}}= & \text { matrix fracture energy; } \\
V_{\mathrm{m}}= & \text { matrix volume fraction; } \\
\Delta U_{\mathrm{f}-\mathrm{mu}}= & \text { increase in the fiber strain energy as the } \\
& \text { result of the bridging action at the end } \\
& \text { of region } \mathrm{I} ;
\end{aligned}
$$




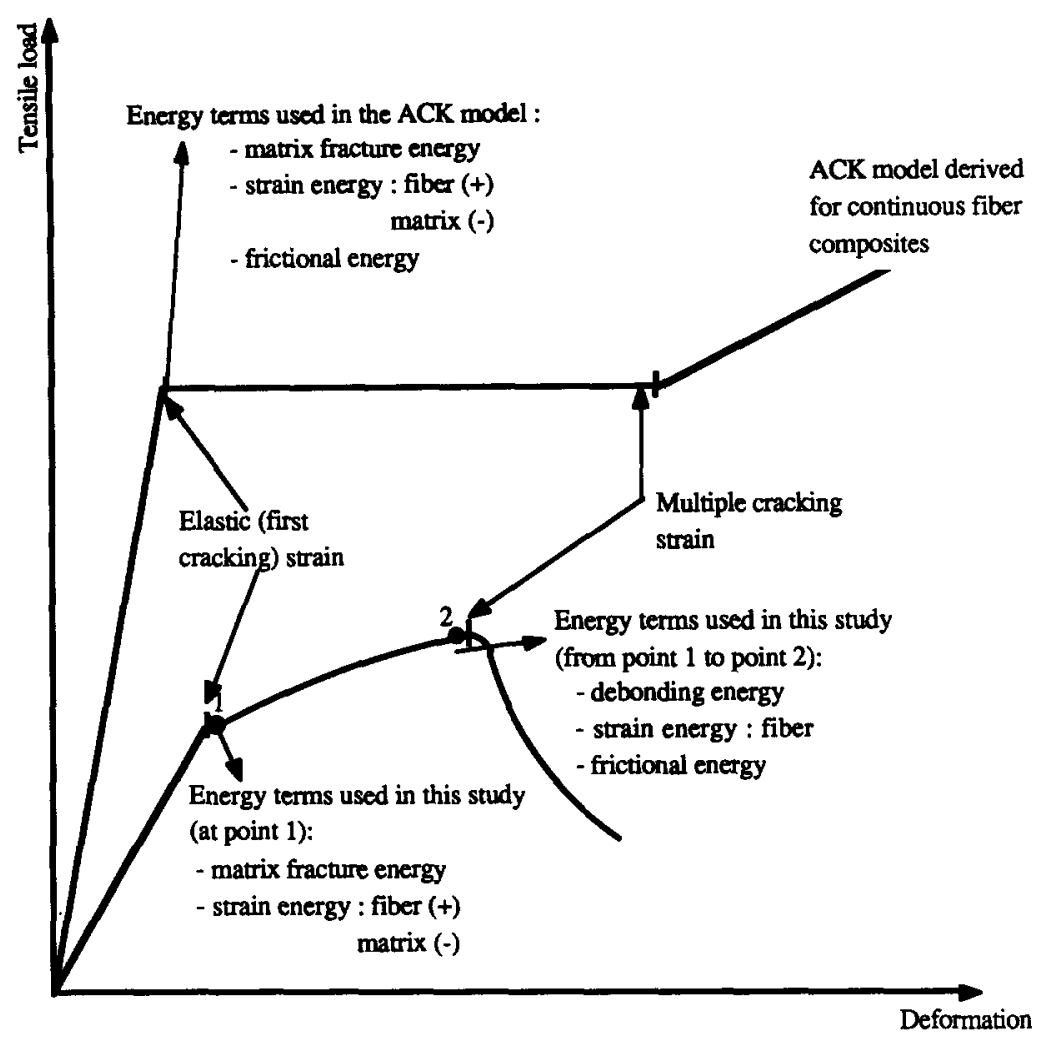

Fig. 4. Energy changes during cracking in continuous and discontinuous fiber composites.

\section{$\Delta U_{\mathrm{m}}=$ decrease in the matrix strain energy since the strain in the matrix at the crack face will be reduced to zero.}

\section{Proposed mechanism of tensile strain hardening in discontinuous FRC}

The strain hardening stage is characterized by the formation of cracks (microcracks) in the composite. These microcracks are not visible to the eye except for a crack occurring just before peak load.

Several researchers such as Hillerborg et al. ${ }^{16-19}$ and Bazant et al. ${ }^{211-23}$ have used the energy approach successfully to model the cracking process in concrete. Although these models are mainly applicable in the failure region where localization occurs, and not in the multiple cracking region, the concept of energy dissipation is useful in understanding the basic mechanism of multiple cracking in discontinuous fiber composites. The occurrence of multiple cracking in discontinuous FRC is sketched in Fig. 5.

The basic concept in understanding multiple cracking is that the energy required to open a microcrack, $E_{1}(1 \rightarrow 2)$, is larger than that required to form a new microcrack, $E_{2}, E_{3}, \ldots, E_{n}$. In Fig. 5 it is assumed that crack number 1 is the first

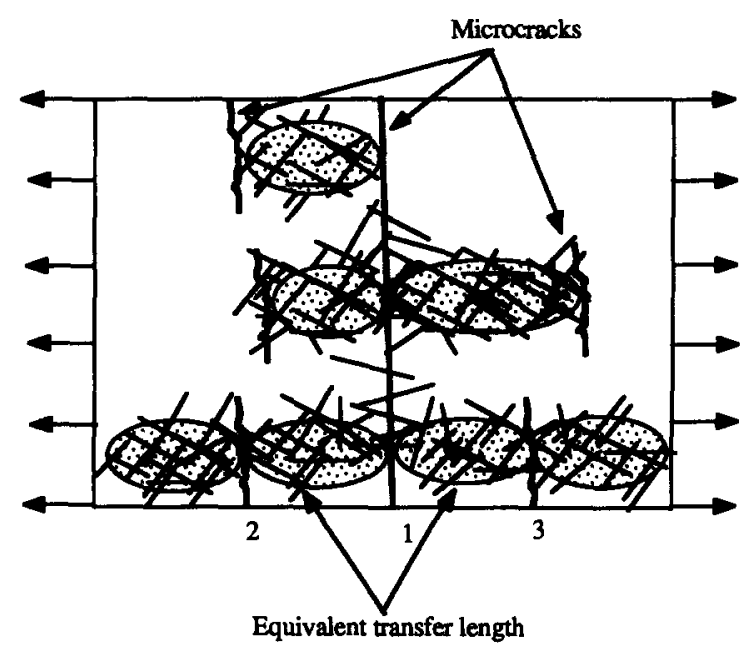

Fig. 5. Multiple cracking in discontinuous FRCs.

microcrack. When this first microcrack opens up, for example, because of increase in loading, the energy required to open the microcrack $\left(E_{1}(1 \rightarrow 2)\right)$ is larger than that to create new microcracks $\left(E_{2}, E_{3}, \ldots, E_{n}\right)$, i.e. microcrack numbers 2 , 3 , etc., up to $n$. During increased loading in region 2 , energy is gradually built up in the composite. If the energy to form a new microcrack, $E_{2}$, $E_{3}, \ldots, E_{n}$, is smaller than the energy to open the first microcrack, $E_{1}(1 \rightarrow 2)$, from point 1 to point 2 (in Fig. 2), i.e. to onset of failure, then multiple 
cracking takes place. Conversely, if multiple cracking takes place, then the energy to open a microcrack is greater than that to form a new microcrack. The microcracking process is repeated until the sum of $E_{2}, E_{3}, \ldots, E_{n+1}$ is larger than $E_{1}(1 \rightarrow 2)$ when the cracking process is terminated, with microcrack number $n$ being the last microcrack formed. In this case, the softening stage is reached and localization occurs at crack number 1 . It is assumed that the magnitude of $E_{2}$ is the same as $E_{3}, \ldots, E_{n}$, since the same energy dissipation mechanisms occur in the formation of a microcrack as shown in eqn (2). In reality, it is expected that $E_{2}$ is lower than $E_{3}$, and $E_{3}$ is lower than $E_{n}$ due to the random strength distribution of the matrix. This means that the third microcrack will be formed at an energy level higher than that for the second microcrack.

It should be pointed out that this concept implies that the first crack will always become the failure crack. In region II, i.e. in the multiple microcracking region, no localization was observed. No unloading of strain gages, which suggests the occurrence of localization, was observed during the tests (up to six strain gages were used for each specimen). Thus, the first microcrack formed was still 'active', i.e. transferring load and opening up, after other microcracks were formed. Since this first crack is more advanced in the microcrack-opening process than the other microcracks, it will eventually open up further to become the failure crack in region III (softening region). The significance of this observation is that the understanding of multiple cracking in discontinuous fiber composites can be simplified by understanding the different energy terms required to open up a microcrack and to form microcracks.

\section{Energy terms and evaluation}

In this section, an example of the application of the proposed mechanism is given. Each of the energy terms in eqns (1) and (2) can be further evaluated. For eqn (1) the expressions obtained $^{24,25}$ for composites reinforced with discontinuous short fibers are shown in eqns (4), (7) and (9). The energy term for the snubbing effect $\left(U_{\mathrm{sb}}\right)$ for a DSP matrix reinforced with short steel fiber was found to be negligible. ${ }^{24}$ However, this term may be significant in FRC containing fibers of low stiffness such as polypropylene and other synthetic fibers.

The energy term for fiber strain energy (in region $\mathrm{II}$ ) is

$$
\begin{gathered}
\Delta U_{\mathrm{f}}=2 V_{\mathrm{f}}\left[\int_{0}^{L_{\mathrm{f}} / \mathrm{t}} \frac{1}{2} E_{\mathrm{f}} \varepsilon_{\mathrm{f} 2}^{2}(x) \mathrm{d} x-\right. \\
\left.\int_{0}^{L_{\mathrm{f}} / 4} \frac{1}{2} E_{\mathrm{f}} \varepsilon_{\mathrm{f} 1}^{2}(x) \mathrm{d} x\right]
\end{gathered}
$$

It is assumed that the average embedment length of fibers at the beginning of pull-out is $L_{\mathrm{f}} / 4$. Also, assuming a strain distribution based on shear-lag theory and carrying out the integration, the following expression for $\Delta U_{\mathrm{f}-\mathrm{mc}}$ can be obtained:

$$
\Delta U_{\mathrm{f}-\mathrm{mc}}=\frac{V_{\mathrm{ef}}}{E_{\mathrm{f}}}\left[\frac{7}{48} \frac{\tau_{\mathrm{f}}^{2} L_{\mathrm{f}}^{3}}{r^{2}}-\left(E_{\mathrm{f}} \varepsilon_{\mathrm{mu}}\right)^{2} \frac{L_{\mathrm{f}}}{4}\right]
$$

where

$V_{\mathrm{ef}}=$ effective volume fraction of fibers;

$V_{\mathrm{f}}=$ volume fraction of fibers;

$E_{\mathrm{f}}=$ modulus elasticity of fiber;

$L_{\mathrm{f}}=$ length of fiber;

$r=$ radius of the fiber;

$\varepsilon_{\mathrm{mu}}=$ first-crack strain of the composite;

$\tau_{\mathrm{f}}=$ frictional interface stress.

For fiber frictional energy:

$$
\Delta U_{\text {ir }- \text { per fiber }}=2 \pi r \int_{0}^{I_{f} / t} \tau_{\mathrm{f}}\left(\varepsilon_{\mathrm{f} 2}(x)-\varepsilon_{\mathrm{mu}}\right) \mathrm{d} x
$$

and

$$
\Delta U_{\mathrm{fr}}=2\left(\frac{V_{\mathrm{f}}}{\pi r^{2}} \times \Delta U_{\mathrm{fr}-\text { per fiber }}\right)
$$

which results in eqn (7):

$$
\Delta U_{\mathrm{fr}}=\frac{V_{\mathrm{ef}} \tau_{\mathrm{f}} L_{\mathrm{f}}^{2}}{4 r}\left[\frac{\tau_{\mathrm{f}} L_{\mathrm{f}}}{3 E_{\mathrm{f}} r}-\frac{1}{2} \varepsilon_{\mathrm{mu}}\right]
$$

For debonding energy:

$$
U_{\mathrm{dh}}=2 \frac{V_{\mathrm{f}}}{\pi r^{2}} \times(2 \pi r) \frac{L_{\mathrm{f}}}{4}\left(G_{\mathrm{II}}\right)
$$

or

$$
U_{\mathrm{db}}=\frac{V_{\mathrm{et}} L_{\mathrm{f}} G_{\mathrm{Il}}}{r}
$$

where $G_{\mathrm{ll}}$ is the fracture energy in the second mode, i.e. in a shearing fracture process, of the fiber-matrix interface. The effective fiber volume fraction:

$$
V_{\text {ef }}=0.5 V_{\mathrm{f}}
$$

Equation (10) was derived in Wang et al. ${ }^{26}$ assuming that the fibers were randomly oriented in 
space with embedment lengths uniformly distributed between 0 and $L_{\mathrm{f}} / 2$.

For eqn (2) the expressions obtained ${ }^{24,27}$ are shown in eqns (12) and (15).

The fiber strain energy in region I:

$$
\begin{gathered}
\Delta U_{\mathrm{f}}=2 V_{\mathrm{ef}}\left[\int_{0}^{L_{2} / 2} \frac{1}{2} E_{\mathrm{f}} \varepsilon_{\mathrm{f}}^{2}(x) \mathrm{d} x-\right. \\
\left.\int_{0}^{L_{\mathrm{f}} / 2} \frac{1}{2} E_{\mathrm{f}} \varepsilon_{\mathrm{mu}}^{2} \mathrm{~d} x\right]
\end{gathered}
$$

In Ref. 25 it was shown that the integration limit was $L_{\mathrm{f}} / 2$. Also, assuming linear strain distribution in the fiber and carrying out the integration, the following expression can be obtained:

$$
\Delta U_{\mathrm{f}-\mathrm{mu}}=\frac{1}{24} E_{\mathrm{f}} V_{\mathrm{ef}} L_{\mathrm{f}} \alpha(18+7 \alpha) \varepsilon_{\mathrm{mu}}^{2}
$$

where

$$
\alpha=\frac{E_{\mathrm{m}} V_{\mathrm{m}}}{E_{\mathrm{f}} V_{\mathrm{f}}}
$$

The decrease in matrix strain energy:

$$
\begin{aligned}
\Delta U_{\mathrm{m}}= & 2 V_{\mathrm{m}}\left[\int_{0}^{L_{\mathrm{f}} / 2} \frac{1}{2} E_{\mathrm{m}} \varepsilon_{\mathrm{mu}}^{2} \mathrm{~d} x-\right. \\
& \left.\int_{0}^{L_{\mathrm{f}} / 2} \frac{1}{2} E_{\mathrm{m}} \varepsilon_{\mathrm{m}}^{2}(x) \mathrm{d} x\right]
\end{aligned}
$$

which result in the following expression:

$$
\Delta U_{\mathrm{m}}=\frac{11}{24} E_{\mathrm{m}} V_{\mathrm{m}} L_{\mathrm{f}} \varepsilon_{\mathrm{mu}}^{2}
$$

where $E_{\mathrm{m}}$ is the modulus elasticity of matrix, and $V_{\mathrm{m}}$ is the volume fraction of matrix.

The contribution to total energy $\left(E_{1}(1 \rightarrow 2)\right.$ and $E_{2}$ ) from each of the energy terms can be evaluated by substituting the matrix and fiber characteristics into each energy expression. The input parameters and other characteristics such as compressive strength and water-cement ratio, for fiber reinforced DSPs are shown in Table 2.

The value of $G_{\text {II }}$ used in the calculations was $120 \mathrm{~N} / \mathrm{m}$. For fiber reinforced DSPs it is reasonable to assume that the value of $G_{I I}$ may be at least the same if not higher than the fracture energy of the matrix of $120 \mathrm{~N} / \mathrm{m}$. The rationale is that the microstructure of the fiber-matrix interface has been significantly improved because of the particle size modification and low water-cement ratio of the DSP matrix. In a study by Bentur $e t$ $a l .{ }^{29-32}$ and Wei et al., ${ }^{33}$ it was shown that the bond strength of the fiber-matrix interface is highly
Table 2. Input parameters and characteristics of fiber reinforced DSP

\begin{tabular}{lc}
\hline \multicolumn{1}{c}{ Materials } & $\begin{array}{c}\text { Fiber } \\
\text { reinforced } \\
D S P\end{array}$ \\
\hline Matrix & \\
Compressive strength & $175 \mathrm{MPa}$ \\
Modulus of elasticity & $49100 \mathrm{MPa}$ \\
Frictional stress & $5 \mathrm{MPa}$ \\
Fracture energy $\left(G_{\mathrm{m}}\right)$ & $120 \mathrm{~N} / \mathrm{m}$ \\
Interface fracture energy $\left(G_{\mathrm{il}}\right)$ & $120 \mathrm{~N} / \mathrm{m}^{a}$ \\
W/C ratio & $0 \cdot 18$ \\
Steel fiber & \\
Modulus of elasticity & $200000 \mathrm{MPa}$ \\
Length & $6 \mathrm{~mm}$ \\
Diameter & $0 \cdot 15 \mathrm{~mm}$ \\
\hline
\end{tabular}

"Estimated.

dependent on the matrix properties such as water-cement ratio and strength, and that the bond strength increases with decreasing watercement ratio. In cement-based FRCs the transition zone, which is $c .10$ to $20 \mu \mathrm{m}$ away from the fiber surface, is associated with bleeding of water around the fiber and inefficient packing of cement particles. The bleeding of water will result in flaws and a higher relative amount of the reaction product calcium hydroxide. These two sources of weakness at the interface may not exist in a DSP matrix because of the low water-cementitious ratio, particle size modification of the matrix, and diminished quantity of calcium hydroxide due to the pozzolanic reaction with microsilica. A high compressive strength due to a low water-tocementitious ratio and the improvement in the microstructure at the interface due to a high proportion of microsilica will generally increase the bond strength significantly.

Another input parameter required is the cracking strain of the composite $\left(\varepsilon_{\mathrm{mu}}\right)$. The $\varepsilon_{\mathrm{mu}}$ value increases with increasing fiber volume fraction as previously reported. ${ }^{24,27,28}$ In this paper, $\varepsilon_{\mathrm{mu}}$ was predicted from the experimental results shown in Fig. 6, using a second-order polynomial fit.

The energy required to open a microcrack, $E_{1}(1 \rightarrow 2)$, for a fiber reinforced DSP matrix is shown in Fig. 7. The values of $E_{1}(1 \rightarrow 2)$ increase with increasing fiber volume fraction. As expected, more energy is required to open a microcrack wth a higher fiber volume fraction.

According to the model, most of this energy expended is associated with the debonding energy $\left(G_{I I}\right)$, which is the energy required to destroy the elastic bond between the fiber and the matrix. 


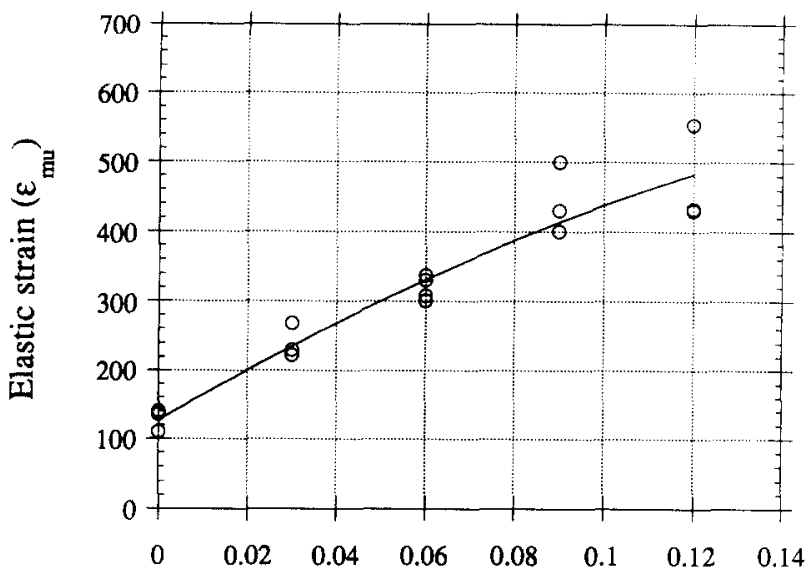

Fiber volume fraction

Fig. 6. Cracking (elastic) strain values used in energy terms evaluation.

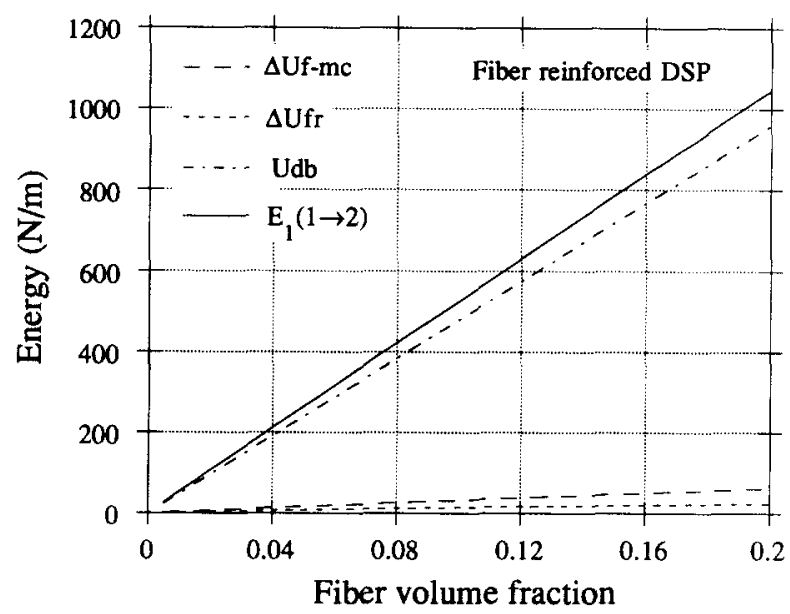

Fig. 7. Predictions of the energy required to open a microcrack in fiber reinforced DSP.

The model predictions of the level of energy required to form a microcrack, $E_{2}$, in a fiber reinforced DSP matrix is shown in Fig. 8.

$E_{2}$ decreases slightly with increasing fiber volume fraction. The reason for this trend is the increase in $\Delta U_{\mathrm{m}}$, which has a negative sign (eqn (2)), and the slight decrease in the contribution of the matrix fracture energy, due to the decrease in matrix volume fraction with the increase in fiber volume fraction.

\section{CONCLUSIONS}

1. Energy expressions associated with the cracking process were developed to explain the mechanism for strain hardening through the occurrence of multiple microcracking in discontinuous fiber composites.

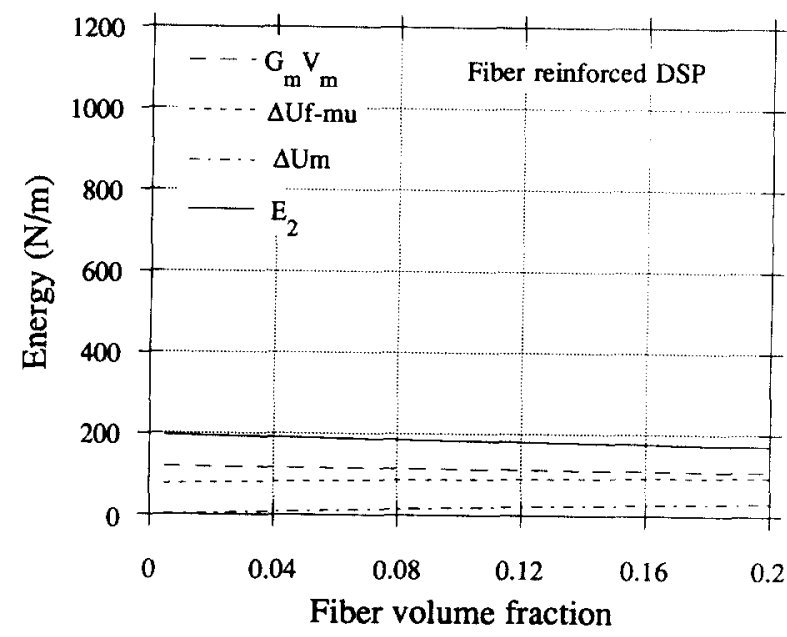

Fig. 8. Predictions of the energy required to form a microcrack in fiber reinforced DSP.

2. Results from flexure tests showed that the addition of strong, fine steel fibers to a brittle material such as a DSP mortar result in a significant strain hardening in the elastic and inelastic strain regions. The total strain capacity increased from 150 microstrain (for plain matrix) to about 2000 microstrain $(0 \cdot 2 \%)$ at $12 \%$ fiber volume fraction. Total load carrying capacity also increased with increasing fiber content. The peak load increased by a factor of five at a $12 \%$ fiber volume fraction.

\section{ACKNOWLEDGEMENTS}

This research was supported in part by a grant from the National Science Foundation to the NSF Center for Advanced Cement Based Materials (Northwestern - 0830-350-B600-UM). The authors would like to thank the Cement and Concrete Laboratory (CBL) of Aalborg Portland for use of their facilities and technical support. The authors would like to thank Messrs $\mathrm{H}$. $\mathrm{H}$. Bache and $\mathrm{B}$. Aarup from CBL for their suggestions and help.

\section{REFERENCES}

1. Shah, S. P., Theoretical models for predicting the performance of fiber reinforced concretes. J. Ferrocement, 18 (3) (July 1988) 263-84.

2. Bache, H. H., Compact reinforced composite basic principles. CBL Report No. 41, Aalborg Portland, Aalborg, Denmark, 1987, pp. 87.

3. Heshe, G., Experimental research on compact reinforced composite (CRC) beams. Danish Society for Structural Science and Engineering, Vol. 59, No. 1, 1988, 1-80. 
4. Naaman, A. E. \& Homrich, J. R., Tensile stress-strain properties of SIFCON. ACI Mater. J., 86 (3) (1989) 244-51.

5. Stang, H., Mobasher, B. \& Shah, S. P., Quantitative damage characterization in polypropylene fiber reinforced concrete. Cement and Concrete Res., 20 (July 1990) 540-58.

6. Mobasher, B., Stang, H. \& Shah, S. P., Microcracking in fiber reinforced concrete. Cement and Concrete Res., 20 (Sept. 1990) 665-79.

7. Mobasher, B., Castro-Montero, A. \& Shah, S. P., A study of fracture in fiber reinforced cement-based composites using laser holographic interferometry. Experimental Mechanics 30 (1990) 286-94.

8. Naaman, A. E. \& Shah, S. P., Fracture and multiple cracking of cementitious composites. In Fracture Mechanics Applied to Brittle Materials, Proc. 11th Nat. Symp. Fracture Mechanics, ed. C. W. Smith \& S. W. Freiman, American Society for Testing and Materials, Philadelphia, 1979, pp. 183-201.

9. Naaman, A. E., High performance fiber reinforced cement composites. Concrete Structures for the Future, IABSE Symp., Paris-Versailles, 1987, pp. 371-6.

10. Jenq, Y. S. \& Shah, S. P., Crack propagation in fiberreinforced concrete. J. Struct. Eng., ASCE, 112 (1) (Jan. 1986) 19-34

11. Wang, Y., Li, V. C. \& Backer, S., Analysis of synthetic fiber pull-out from a cement matrix. In Bonding in Cementitious Composites, Mater. Res. Soc. Symp. Proc., Vol. 114, ed. S. Mindess \& S. P. Shah, Materials Research Society, Pittsburgh, 1988, pp. 159-65.

12. Shah, S. P. \& Jenq, Y. S., Fracture mechanics of interfaces. In Bonding in Cementitious Composites, Mater. Res. Soc. Symp. Proc., Vol. 114, ed. S. Mindess \& S. P. Shah, Materials Research Society, Pittsburgh, 1988, pp. 205-16.

13. Nammur, G., Naaman, A. E. \& Clark, S. K., Analytical prediction of the pull-out behavior of steel fibers in cementitious matrices. In Bonding in Cementitious Composites, Mat. Res. Soc. Symp. Proc., Vol. 114, ed. S. Mindess \& S. P. Shah. Materials Research Society, Pittsburgh, 1988, pp. 217-24.

14. Morrison, J. K., Shah, S. P. \& Jenq, Y. S., Analysis of fiber debonding and pullout in composites. $J$. Eng. Mech. Div., ASCE, Vol. 114, No. 2, February 1988, pp. 277-94.

15. Aveston, J., Cooper, G. A. \& Kelly, A., Single and multiple fracture. In The properties of fibre composites. Conf. Proc. National Physical Laboratory, IPC Science and Technology Press Ltd, 1971, pp. 15-24.

16. Hillerborg, A., Modeer, M. \& Petersson, P. E., Analysis of crack formation and crack growth in concrete by means of fracture mechanics and finite elements. Cement and Concrete Res., 6, 773-82.

17. Hillerborg, A., Analysis of fracture by means of the fictitious crack model, particularly for fibre reinforced con- crete. Int. J. Cement Composites, 2 (4) (1980) 177-84.

18. Hillerborg, A., Numerical methods to simulate softening and fracture of concrete. In Fracture Mechanics of Concrete: Structural Application and Numerical Calculation, Kluwer Academic, 1985, pp. 141-70.

19. Hillerborg, A., Analysis of one single crack. Fracture Mechanics of Concrete, ed. F. H. Wittmann. Elsevier, London, 1983, pp. 223-49.

20. Bazant, Z. P. \& Cedolin, L., Blunt crack band propagation in finite element analysis. J. Eng. Mech. Div., ASCE, 105 (EM2) (April 1979) 297-315.

21. Bazant, Z. P. \& Cedolin, L., Fracture mechanics of reinforced concrete. J. Eng. Mech. Div., ASCE, 106 (EM6) (Dec. 1980) 1287-306.

22. Bazant, Z. P., Crack band model for fracture of geomaterials. Proc. 4th Int. Conf. Numerical Methods in Geomechanics, A. A. Balkema. Rotterdam, 1982, pp. 1137-52.

23. Bazant, Z. P. \& Oh, B.H., Crack band theory for fracture of concrete. Materials and Structures, 16 (1983) 155-77.

24. Tjiptobroto, P., Tensile strain hardening of high performance fiber reinforced cement-based composites. PhD dissertation, University of Michigan, Ann Arbor, 1991.

25. Tjiptobroto, P. \& Hansen, W., Tensile strain hardening - inelastic strain. (to be submitted to ACI Materials J.)

26. Wang, Y., Backer, S. \& Li, V. C., A statistical tensile model of fibre reinforced cementitious composites. Composites, 20 (3) (May 1989) 265-74.

27. Tjiptobroto, P. \& Hansen, W., A model for predicting the improvement in elastic strain of FRC's containing high volume fraction of discontinuous fibers. $A C I$ Materials $J$. (submitted).

28. Tjiptobroto, P. \& Hansen, W., Flexural behavior of ultra-high strength concrete with high volume fraction of discontinuous steel fibers. In Advances in Cementitious Composites-Ceramic Transactions, Vol. 16, ed. S. Materials J. (submitted).

29. Bentur, A., Diamond, S. \& Mindess, S., Cracking processes in steel fibre reinforced cement paste. Cement and Concrete Res., 15 (2) (1985) 331-42.

30. Bentur, A., Diamond, S. \& Mindess, S., The microstructure of the steel fibre-cement interface. J. Mater. Sci., $20(10)(1985)$ 3610-20.

31. Bentur, A., Fiber-reinforced cementitious materials. In Materials Science of Concrete, ed. J. P. Skalny. American Ceramic Society, Westerville, OH, 1990, pp. 223-83.

32. Bentur, A., Interfaces in fibre reinforced cements. In Bonding in Cementitious Composites, Mater. Res. Soc. Symp. Proc., Vol. 114, eds S. Mindess \& S. P. Shah, Materials Research Society, Pittsburgh, 1988, pp. 133-44.

33. Wei, S., Mandel, J. A. \& Said, S., Study of the interface strength in steel fiber-reinforced cement-based composites. ACI J., Proc., 83 (4) (1986) 597-605. 